\title{
Public Goods, Unemployment and Policy Coordination*
}

\author{
Thomas Aronsson ${ }^{\dagger}$ \\ Umeå University \\ Sven Wehke \\ University of Magdeburg
}

November 2006

\begin{abstract}
Earlier literature on tax competition and policy coordination typically assumes that the labor market is competitive; a description less suitable for Europe, where trade unions have had a strong position in the labor market for a long time. This paper concerns factor income taxation and public good provision in small open economies characterized by capital mobility and imperfect competition in the labor market. We assume that each national government collects public revenues via taxes on labor, capital and profit income, and that the revenues are spent on a public consumption good and a public input good, where the latter enters the economic system in terms of an 'externality production factor'. The overall purposes are to characterize the tax and expenditure policies, if decided upon at the national level, and analyze the welfare effects of policy coordination with respect to taxes and public expenditures. Among the results, we show that tax coordination contributes to higher welfare if it reduces the net interest rate and the wage rate, and that the relative overprovision of the public input good derived by Keen and Marchand (1997) in the context of a competitive economy may no longer hold, if the labor market is non-competitive.
\end{abstract}

JEL Classification: H21, H41, J51

Keywords: optimal taxation, wage bargaining, public goods, policy coordination

*The authors would like to thank Ronnie Schöb and Tomas Sjögren for helpful comments and suggestions. Financial support by the DAAD and STINT is also gratefully acknowledged.

†Department of Economics, Umeå University, SE - 90187 Umeå, Sweden, Email: thomas.aronsson@econ.umu.se.

$\ddagger$ Otto-von-Guericke-University Magdeburg, Faculty of Economics and Management, P.O. Box 41 20, 39016 Magdeburg, Germany, Email: sven.wehke@ww.uni-magdeburg.de. 


\section{Introduction}

As productive capital is mobile across countries, it has been recognized that independent national governments have incentives to adjust their public policies in order to compete for mobile capital. Earlier literature dealing with fiscal competition and/or policy coordination (in order to internalize the associated externalities) has focused much attention on tax policy ${ }^{1}$. A major result is that tax competition leads to undertaxation of capital (at least if the economies are characterized by competitive markets) which may, in turn, give rise to underprovision of public goods relative to the first best ${ }^{2}$. However, much less attention has been paid to the related issue of how the tax revenues are spent, i.e. the mix of public expenditures. An important exception is Keen and Marchand (1997), who make a distinction between a public consumption good, which enters the economic system via the utility function, and a public input good entering as an 'externality production factor'. In their study, the set of tax instruments contains linear taxes on labor and capital and a (nondistortionary) profit tax. If, as they assume, the nondistortionary tax instrument does not raise enough revenues (meaning that distortionary taxes must be used), the results show that the public input good will be inefficiently large relative to the public consumption good in an uncoordinated equilibrium, where each national government behaves as a Nash competitor. The intuition in terms of their model is that the public consumption good does not, itself, give rise to externalities, whereas the public input good strengthens the externality caused by the competition for mobile capital.

The literature discussed above is based on the assumption of competitive markets. In this paper, we relax the assumption that the labor market is competitive and assume, instead, that the wage rate is decided upon by bargaining between unions and firms, meaning that the equilibrium is characterized by involuntary unemployment. Given this description of the labor market, our paper deals with factor income taxation and public good provision in small open economies competing for mobile capital. To be able to address the mix of public expenditures, we follow Keen and Marchand in the sense of distinguishing between a public consumption good and a public input good, while the set of tax instruments contains linear taxes on labor and capital and a nondistortionary profit tax. The overall purposes are to characterize the tax and expenditure policies, if decided upon at the national

\footnotetext{
${ }^{1}$ See e.g. Wilson (1986), Zodrow and Mieszkowski (1986) and Mintz and Tulkens (1986). See also Wilson (1999) for an overview.

${ }^{2}$ Bucovetsky and Wilson (1991) show that also labor taxes tend to be too low in an uncoordinated equilibrium.
} 
level, and analyze the welfare effects of policy coordination with respect to taxes and public expenditures.

There are several reasons for considering imperfect competition in the labor market in the context of optimal taxation and public goods. First, unions are important institutions, at least in a European context, suggesting that the introduction of imperfect competition in the labor market provides additional realism to the study of taxation, public goods and policy coordination. Considering that many countries have experienced high rates of unemployment for a long time, it is clearly relevant to extend the theory of fiscal competition accordingly. Second, by analyzing the mix of public goods more thoroughly in the context of fiscal competition, our study provides a complement to the literature developed so far on optimal taxation and public provision (of public and private goods) in economies with involuntary unemployment ${ }^{3}$.

Policy coordination under imperfect competition in the labor market has been addressed by Lejour and Verbon (1996) and Fuest and Huber (1999). Lejour and Verbon analyze social insurance financed by labor income taxation in a two-country economy. In their study, where a monopoly union characterizes the labor market, capital mobility leads to undertaxation in an uncoordinated equilibrium. As a consequence, a coordinated tax increase leads to higher welfare. Fuest and Huber consider fiscal competition and policy coordination in small open economies with right-to-manage wage formation. They assume that the set of tax instruments facing each national government consists of linear taxes on labor and capital and a 100 per cent profit tax, while the expenditure side includes a public consumption good. Their main contribution is then to show that coordinated labor and capital tax increases will not necessarily increase the welfare, if the labor market is characterized by right-to-manage wage formation ${ }^{4}$ (coordinated increases in the labor and capital taxes would increase welfare in their model, if the labor market were competitive).

Our paper differs from the aforementioned studies in several ways. One such difference is that we pay more attention to the expenditure side by considering the mix of public goods; as such our paper is connected to the study by Keen and Marchand. In addition, the distinction between two types of public goods

\footnotetext{
${ }^{3}$ See e.g. Marceau and Boadway (1994), Fuest and Huber (1997), Koskela and Schöb (2002), Aronsson and Sjögren (2004a) and Aronsson et al. (2005).

${ }^{4}$ There are other possible reasons for policy coordination in open economies characterized by right-to-manage wage formation. For instance, firms might move abroad in case the bargain fails. This means that the wage formation system gives rise to an international externality (as the reservation profit is determined abroad and treated as exogenous in the context of domestic public policy) which, in turn, motivates policy coordination; see Aronsson and Sjögren (2004b).
} 
also enables us to address the interesting issue of how the additional tax revenues, following a coordinated increase in each of the tax instruments, are spent. To be more specific, our paper contributes to the literature in two ways. The first is by characterizing the uncoordinated equilibrium, which is based on the assumption that each small country treats the world interest rate as well as the policies chosen by other countries as exogenous. The second is by considering policy coordination, where we examine the welfare effects of (i) an increase in each of the tax rates, while allowing the additional tax revenues to be spent either on the public consumption good or the public input good, and (ii) a revenue neutral reallocation of the public expenditures. Among the results, we show that tax coordination contributes to higher welfare if it reduces the net interest rate and the wage rate, and that the relative overprovision of the public input good derived by Keen and Marchand may no longer hold, if the labor market is non-competitive.

The paper is organized as follows. In section 2, we describe the model and analyze the outcome of private optimization. Section 3 characterizes the uncoordinated Nash equilibrium from the perspective of public policy. The welfare effects of policy coordination are analyzed in section 4 . Section 5 summarizes and concludes.

\section{The model}

Since our analysis does not address redistribution, we simplify by considering a representative-agent economy, where the agent (or household) is rationed in the labor market. The utility function is written

$$
U=U(C, G)
$$

where $C$ is a private consumption good and $G$ a public consumption good. We assume that $U(\cdot)$ is increasing in both arguments and strictly quasiconcave. The budget constraint is given by

$$
C=\rho \bar{K}+\omega L+(N-L) b+\left(1-t_{s}\right) \pi,
$$

in which $\rho$ is the net interest rate, $\bar{K}$ the capital endowment, $\omega$ the net wage rate, $L$ employment, $b$ the monetary value attached to leisure by the consumer ${ }^{5}, \pi$ the profit

\footnotetext{
${ }^{5}$ An alternative interpretation of $b$ would be in terms of an unemployment benefit. However, in order to avoid unnecessary structure (from the point of view of the purpose of the paper), unemployment benefits are not part of the choice set facing the government. This simplification is not important for the qualitative results to be derived below.
} 
income and $t_{s}$ the profit tax rate. If $N$ is thought of as 'the number of household members', then $L$ is interpretable as the number of household members who are in employment. The gross wage rate and interest rate are defined as $w=\omega\left(1+t_{w}\right)$ and $r=\rho\left(1+t_{c}\right)$, respectively, where $t_{w}$ is the labor tax rate and $t_{c}$ the capital tax rate.

Turning to the production side of the economy, the representative firm produces a homogenous good by using labor, capital and the public input good, $P$. The public input good works as an 'externality production factor' in the sense that it is exogenous to the firm. We assume that the public input good raises the productivity of private factors and does not itself generate profits, meaning that the number of firms in each country is not important for the analysis and can be normalized to one $^{6}$. However, in order to formalize the wage bargaining part of the model (see below), we also require that the firms produce rents to bargain over. Therefore, the production function, $F(K, L, P)$, exhibits decreasing returns to scale in the private production factors, so $F_{K K} F_{L L}-\left(F_{K L}\right)^{2}>0$. The objective function of the firm is written as

$$
\pi=F(K, L, P)-w L-r K,
$$

where the output price has been normalized to one for notational convenience. The firm chooses labor and capital to maximize profits, which gives the factor demand functions,

$$
\begin{gathered}
K=K(w, r, P), \\
L=L(w, r, P),
\end{gathered}
$$

and the profit function

$$
\pi=\pi(w, r, P)
$$

The net wage rate is determined by bargaining between unions and firms, and wage formation is decentralized. The latter is interpreted to mean that each union is small enough to treat economy-wide aggregates as well as the government's decision variables as exogenous, which is a reasonable description of the wage formation system in many countries. By analogy to the treatment of the production sector, the number of unions will be normalized to one. If we define $C^{0}=\rho \bar{K}+N b+\left(1-t_{s}\right) \pi$ and $U^{0}=U\left(C^{0}, G\right)$ to be the consumption and utility, respectively, of the household

\footnotetext{
${ }^{6}$ See e.g. McMillan (1979) and Matsumoto (1998).
} 
in case the bargain fails, the rent for the union from the bargain becomes $\Upsilon=$ $U-U^{0}$. The profit income accruing to each household is its share of the aggregate (economy-wide) profit, and we assume that this measure of profit income is treated as exogenous in the context of a single firm-union bargain. The rent for the firm is equal to the net profit it earns in the production since its reference profit (which applies in case the bargain fails) is equal to zero. The outcome of the bargain will be the net wage rate which maximizes the generalized Nash product

$$
\Omega=\Upsilon^{a}\left[\left(1-t_{s}\right) \pi\right]^{1-a},
$$

where $a$ is the bargaining power of the union. Following earlier literature on optimal taxation under imperfect competition in the labor market, we assume that the union is acting Stackelberg leader vis-a-vis the household during wage formation. By substituting equations (2), (4) and (5) into equation (7), we can use the resulting first order condition to write the net wage rate as a function of the policy variables, $t_{w}, t_{c}, G$ and $P$, and of the net interest rate,

$$
\omega=\omega\left(t_{w}, r, \rho, P, G\right) .
$$

Note that the profit tax vanishes from the first order condition and is, therefore, not an argument in the wage equation. For later use, note also that the net interest rate, $\rho$, influences the net wage rate via two channels; (i) as a separate argument (which captures a pure income effect on $\Upsilon$ ) and (ii) as an indirect effect via the gross interest rate, $r=\left(1+t_{c}\right) \rho$. The parameters $a$ and $b$ have been suppressed for notational convenience.

\section{Noncooperative Nash equilibrium}

Let us begin by considering the tax and expenditure policies in a noncooperative Nash equilibrium, where each national government treats the policy instruments of the other countries as exogenous. The order of decision-making is such that the government is first mover and recognizes how the private sector (including the union) responds to its policies, while the private sector is follower. The objective function of the national government is the indirect utility function of the representative household, which is obtained by substituting equations (2), (4), (5) and (6) into equation $(1)$;

$$
\begin{aligned}
V & =U\left(\rho \bar{K}+\omega\left(t_{w}, r, \rho, P, G\right) L(w, r, P)+(N-L(w, r, P)) b\right. \\
& \left.+\left(1-t_{s}\right) \pi(w, r, P), G\right)
\end{aligned}
$$


in which we also recognize that the net wage rate is endogenous from the perspective of the government and given by equation (8). In addition, recall that $w=\left(1+t_{w}\right) \omega$ and $r=\left(1+t_{c}\right) \rho$, where the government treats $\rho$ as constant as we are considering a small open economy. The government's budget constraint can be written as

$$
t_{s} \pi(w, r, P)+t_{w} \omega\left(t_{w}, r, \rho, P, G\right) L(w, r, P)+t_{c} \rho K(w, r, P)-G-P=0,
$$

where we assume that the marginal rates of transformation between the private and the public goods are equal to one. Furthermore, following earlier literature on factor income taxation ${ }^{7}$, we also recognize the possibility that profit taxation is restricted. Let $0 \leq \bar{t}_{s} \leq 1$ be the upper limit of the profit tax and write the constraint on the profit tax as follows;

$$
\bar{t}_{s}-t_{s} \geq 0
$$

The decision problem of the national government is to choose $t_{w}, t_{c}, t_{s}, G$ and $P$ in order to maximize the indirect utility function given by equation (9) subject to the budget constraint and the maximum restriction on the profit tax. By using the short notation

$$
R=t_{s} \pi(w, r, P)+t_{w} \omega\left(t_{w}, r, \rho, P, G\right) L(w, r, P)+t_{c} \rho K(w, r, P),
$$

the Lagrangean can be written as

$$
\mathcal{L}=V+\lambda[R-P-G]+\mu\left[\bar{t}_{s}-t_{s}\right]
$$

The tax policy implications following from a simplified version of the decisionproblem (where the utility function is linear in private consumption) has been addressed by Koskela and Schöb (2002). It is, nevertheless, instructive to begin by briefly discussing the tax structure chosen by the national government, since the characteristics of this tax structure will be used in the analysis of policy coordination in the next section. Define $\hat{\lambda}=\lambda / U_{C}$ to be the marginal cost of public funds in real terms, where $U_{C}=U_{C}(C, G)=\partial U(C, G) / \partial C$ is the marginal utility of consumption, and let $\hat{\mu}=\mu / U_{C}$ be the shadow price of the profit tax in real terms. We also introduce the short notations $\omega_{t_{w}}=\partial \omega / \partial t_{w}, \omega_{t_{c}}=\partial \omega / \partial t_{c}$ and $w_{t_{w}}=\partial w / \partial t_{w}$. Consider Proposition 1;

Proposition 1 In the noncooperative Nash equilibrium, the tax structure is characterized by

$$
(\hat{\lambda}-1) \pi-\hat{\mu}=0
$$

\footnotetext{
${ }^{7}$ See e.g. Koskela and Schöb (2002).
} 


$$
t_{w}=\frac{(\hat{\lambda}-1)}{\hat{\lambda}}\left[\frac{\omega_{t_{c}}}{w_{t_{w}}} \frac{L}{\rho} F_{K L}+\frac{\omega_{t_{w}}}{w_{t_{w}}} \frac{L}{\omega} F_{L L}-\left(1-\bar{t}_{s}\right) \frac{K F_{K L}+L F_{L L}}{\omega}\right]-\frac{(\omega-b)}{\hat{\lambda} \omega}
$$

and

$$
t_{c}=\frac{(\hat{\lambda}-1)}{\hat{\lambda}} \frac{1}{\rho}\left[\frac{\omega_{t_{c}}}{w_{t_{w}}} \frac{\omega L}{\rho} F_{K K}+\frac{\omega_{t_{w}}}{w_{t_{w}}} L F_{L K}-\left(1-\bar{t}_{s}\right)\left(K F_{K K}+L F_{L K}\right)\right],
$$

where $F_{L L}, F_{K K}$ and $F_{L K}=F_{K L}$ are second order partial derivatives of the production function.

Proof: see the Appendix.

Note first that, if the constraint on the profit tax is binding, so $\hat{\mu}>0$, it follows that $t_{s}=\bar{t}_{s}$ and $\hat{\lambda}>1$. In other words, if the government must use distortionary taxes, then the marginal cost of public funds exceeds one. Except for the final term in the expression for $t_{w}$, which reflects the incentive for the government to subsidize labor due to the presence of involuntary unemployment, the expressions for $t_{w}$ and $t_{c}$ share a similar structure. In each tax formula, the terms within the bracket reflect the desire to raise revenues by means of distortionary taxes in an efficient way; the first two terms appear because the two tax rates affect the net wage rate, and the third arises because labor and capital taxes constitute indirect means of taxing profit as long as $\bar{t}_{s}<1$. On the other hand, if $\bar{t}_{s}=1$ (and, of course, provided that the constraint on the profit tax is binding), the third term within the bracket of each formula vanishes. These effects are well understood from earlier research - let be in a slightly different framework than ours - and need not be further discussed here.

Given the choice of tax structure, what factors characterize the optimal mix of public goods from the perspective of each individual country? Let subindices attached to $w(\cdot), \omega(\cdot), \pi(\cdot), U(\cdot), L(\cdot), K(\cdot)$ and $F(\cdot)$ denote partial derivatives and consider Proposition 2;

Proposition 2 In the noncooperative Nash equilibrium, the provision of public goods is characterized by

$$
\begin{gathered}
F_{P}-1=\frac{(\hat{\lambda}-1)}{\hat{\lambda}}\left[\omega_{P} L+\left(1-\bar{t}_{s}\right)\left(\pi_{P}+\pi_{w} w_{P}\right)\right]-\frac{(\omega-b)}{\hat{\lambda}}\left[L_{P}+L_{w} w_{P}\right] \\
-t_{w} \omega\left[L_{P}+L_{w} w_{P}\right]-t_{c} \rho\left[K_{P}+K_{w} w_{P}\right] \\
\frac{1}{\hat{\lambda}} \frac{U_{G}}{U_{C}}-1=\frac{(\hat{\lambda}-1)}{\hat{\lambda}}\left[\omega_{G} L+\left(1-\bar{t}_{s}\right) \pi_{w} w_{G}\right]-\frac{(\omega-b)}{\hat{\lambda}} L_{w} w_{G} \\
-t_{w} \omega L_{w} w_{G}-t_{c} \rho K_{w} w_{G} .
\end{gathered}
$$


The proof is analogous to the proof of Proposition 1. Each formula in Proposition 2 is written in terms of the way in which it deviates from the corresponding optimality rule, which applies when public expenditures have no impact on the domestic real variables. The main difference between the two formulas is that, whereas the public input good gives rise to direct effects on the profit and factor employment $\left(\pi_{P}=F_{P}, L_{P}\right.$ and $K_{P}$ in the equation for the provision of $P$ ), the public consumption good only affects the profit and factor employment indirectly via the wage rate $^{8}$. Note that, in the absence of these effects, the public input good would obey the first best policy rule, $F_{P}=1$, while the public consumption good would be characterized by a modified second best rule, $U_{G} / U_{C}=\hat{\lambda}$ (which is equivalent to the first best rule if $\hat{\lambda}=1$ ).

The first term on the right hand side of each expression is due to the use of distortionary taxes. Since $\hat{\lambda}>1$, it follows that the marginal benefit of lump-sum income for the private sector, $U_{C}$, falls short of the marginal cost for society if the government were to claim these additional resources via distortionary taxation, $\lambda$. This necessitates, in turn, that the public good is adjusted, if it affects the private income and tax revenues to the same extent. It is this adjustment that the first term on the right hand side accomplishes. The second part of the first row is due to the presence of involuntary unemployment. If public provision gives rise to increased (decreased) employment, ceteris paribus, this constitutes an incentive for the government to provide more (less) of the public good than it would otherwise have done. Note also that this effect becomes less important, relative to the other components, the higher the marginal cost of public funds. In other words, the greater the cost for society of raising additional tax revenues, the weaker will be the incentive to adjust the provision of the public good in order to increase the employment. The second row of each formula reflects tax base effects, which are defined conditional on the tax rates. The intuition is that increased public provision may either exacerbate or counteract the preexisting tax distortions, depending on how the public provision affects the tax base. Since the public revenues are costly to raise, this constitutes an incentive for the government to modify the public provision. Therefore, if the provision of public goods increases (decreases) the tax revenues, then the government spends more (less) on public provision than it would otherwise have done.

\footnotetext{
${ }^{8}$ See the Appendix for a discussion of how $P$ and $G$ affect the wage rate.
} 


\section{Policy Coordination}

Since the countries compete for a fixed worldwide capital stock, the policy outcome of the noncooperative Nash equilibrium described in Section 3 is not optimal from the perspective of society as a whole, defined as the group of countries. The intuition is, of course, that each national government treats the net interest rate as given, whereas it is an endogenous variable for society as a whole. In this section, we analyze the welfare effects of policy coordination with respect to tax and expenditure policies. Note, however, that we are not discussing how such agreements are formed; only their welfare effects if they are agreed upon and carried out. To simplify the analysis, we assume that the initial equilibrium is symmetric.

\subsection{Tax coordination}

We analyze tax coordination in the sense that the capital tax rate (labor tax rate) is marginally increased by all countries, while the labor tax rate (capital tax rate) is held constant, i.e. $d t_{i}>0$ and $d t_{j}=0, i, j=c, w$ and $i \neq j$. To begin with, let us consider the factor price changes in response to such a joint increase in $t_{i}$ without taking into account how the resulting increase in expenditures affect the factor prices. This enables us to better distinguish the differential welfare effects of public expenditures to be discussed later. If all countries jointly increase their tax on factor $i, t_{i}$, worldwide capital allocation is not affected. In a symmetric equilibrium, each country must still employ its capital endowment

$$
\bar{K}=K(w, r, P) .
$$

Differentiating equations (8) and (14) with respect to the factor prices and the tax rate $t_{i}$, while holding $G$ and $P$ (as well as the other tax instruments) constant, we obtain the following factor price reactions

$$
\begin{aligned}
\left.\rho_{t_{i}}\right|_{\text {coord. }} & =-\frac{d K / d t_{i}}{d K / d \rho} \\
\left.r_{t_{i}}\right|_{\text {coord. }} & =r_{t_{i}}+\left.\left(1+t_{c}\right) \cdot \rho_{t_{i}}\right|_{\text {coord. }}, \\
\left.\omega_{t_{i}}\right|_{\text {coord. }} & =\omega_{t_{i}}+\left.\frac{d \omega}{d \rho} \cdot \rho_{t_{i}}\right|_{\text {coord. }}, \\
\left.w_{t_{i}}\right|_{\text {coord. }} & =w_{t_{i}}+\left.\frac{d w}{d \rho} \cdot \rho_{t_{i}}\right|_{\text {coord. }},
\end{aligned}
$$

where $d K / d \rho=K_{r} r_{\rho}+K_{w} d w / d \rho<0$. Consequently, and in contrast to the uncoordinated case, a joint increase in tax rate $t_{i}$ alters the net interest rate according 
to equation (15). Equations (16)-(18) show that the impact on each of the other factor prices can be decomposed into two effects. The first term on the right hand side represents the factor price change that is also present in case of a unilateral tax increase, i.e. at a constant $\rho$, which will be referred to as the 'autarky effect'. The second term is the additional effect due to the change in the net interest rate, i.e. the 'coordination effect'.

A joint tax increase carried out by all countries generates additional tax revenues for each government, which are to be spent on public goods. This causes, in turn, a change in the net interest rate. From equations (8) and (14), we can derive for the public consumption good

$$
\left.\rho_{G}\right|_{\text {coord. }}=-\frac{K_{w} w_{G}}{d K / d \rho}
$$

while the associated changes in the gross interest rate and the wage rate are derived in the same way as equations (16)-(18). If, on the other hand, the additional tax revenues are spent on the public input good, we have

$$
\left.\rho_{P}\right|_{\text {coord. }}=-\frac{K_{P}+K_{w} w_{P}}{d K / d \rho}
$$

again affecting the remaining factor prices in the same principal way.

We are now in the position to analyze the welfare effects of a marginal tax coordination. Let $W$ be the national welfare function for any of the countries involved, so $W=U(C, G)$, where all entities are evaluated at the noncooperative Nash equilibrium described in the previous section. In addition, note that the welfare function equals the Lagrangean at the noncooperative Nash equilibrium, so $W=\mathcal{L}$. We can derive the following result;

Proposition 3 Starting in the noncooperative Nash equilibrium and holding tax rate $t_{j}$ constant, the welfare effect of a joint increase in tax $t_{i}, i=c, w, i \neq j$, is given by

$$
\left.\frac{d W}{d t_{i}}\right|_{\text {coord. }} ^{d P=0}=\left.\left(V_{\rho}+\lambda R_{\rho}\right) \rho_{t_{i}}\right|_{\text {coord. }}+\left.\left.\left(V_{\rho}+\lambda R_{\rho}\right) \rho_{G}\right|_{\text {coord. }} \cdot R_{t_{i}}\right|_{\text {coord. }},
$$

if the additional tax revenue is spent on the public consumption good, and by

$$
\left.\frac{d W}{d t_{i}}\right|_{\text {coord. }} ^{d G=0}=\left.\left(V_{\rho}+\lambda R_{\rho}\right) \rho_{t_{i}}\right|_{\text {coord. }}+\left.\left.\left(V_{\rho}+\lambda R_{\rho}\right) \rho_{P}\right|_{\text {coord. }} \cdot R_{t_{i}}\right|_{\text {coord. }},
$$

if the additional tax revenue is spent on the public input good.

According to Proposition 3, the welfare effect following tax coordination crucially depends on how the net interest rate responds to the policy variables. Each 
formula in the proposition is a straightforward consequence of the Envelope theorem: although a coordinated increase in one of the tax rates (with the other tax instruments held constant) causes a change in the real allocation by altering the gross factor prices, there are no welfare changes associated with the autarky effect mentioned above. This is so because each national government has already made an optimal policy choice conditional on the net interest rate. Therefore, as the change in the net interest rate is the only additional effect in case of policy coordination, it is the only source of welfare change in this framework.

We show in the appendix that the welfare effect of an increase in the net interest rate can be written as

$$
V_{\rho}+\lambda R_{\rho}=-U_{C}(\hat{\lambda}-1)\left[K+\frac{\omega_{\rho}}{w_{t_{w}}} \omega L\right] .
$$

The right hand side of this expression is decomposable into two parts. First, since $\hat{\lambda}>1$, we have $-U_{C}(\hat{\lambda}-1) K<0$. The intuition is that, to the extent that policy coordination reduces the net interest rate, this is associated with a lump-sum transfer from the capital owners to the government, which unambiguously increases welfare. Second, a change in the net interest rate affects the union's rent from bargaining which, in turn, influences the net wage rate. To provide some intuition behind the latter effect, notice that $w_{t_{w}}>0$, so $-U_{C}(\hat{\lambda}-1) \omega L / w_{t_{w}}<0$. Therefore, the second part of the expression for $V_{\rho}+\lambda R_{\rho}$ is negative (positive) if $\omega_{\rho}>0(<0)$; we derive an expression for $\omega_{\rho}$ in the appendix. We show that the sign of the expression

$$
\frac{U_{C C}}{U_{C}}-\frac{U_{C}-U_{C}^{0}}{\Upsilon}
$$

determines how the net wage rate responds an increase in the net interest rate (with the gross interest rate held constant). The second term in the above expression is the change in the union's rent from bargaining, whereas the first reflects that the value the union attaches to a higher net wage rate decreases with the level of private consumption (conditional on the rent). If the second term dominates, then $\omega_{\rho}>0$. The intuition is that a lower wage rate contributes to increased employment which, in turn, increases welfare in an economy with involuntary unemployment. Therefore, if $\omega_{\rho}>0$, we have $V_{\rho}+\lambda R_{\rho}<0$, implying that a decrease in the net interest rate is welfare improving. The same result will, of course, apply in the special case where the utility is linear in private consumption ${ }^{9}$, as this case means that the net wage

\footnotetext{
${ }^{9}$ Note that the wage rate is also unaffected, if we (instead of dividing the profits equally among the households) define a separate group of households, called capital owners, the members of which receive all profit income. In this case, $\rho$ will have no direct effect on the wage rate.
} 
rate does not depend directly on $\rho$.

Note once again that the first term on the right hand side of equations (21) and (22), respectively, denotes the welfare effect of a joint increase in $t_{i}(i=w, c)$, with the other tax instruments held constant, irrespective of whether the additional tax revenue is spent on $G$ or $P$. The second term, on the other hand, shows the additional welfare effect caused by increased provision of public goods. As such, the latter effect must be weighted by the additional tax revenues, which determines the extent to which the public provision can be increased (provided, of course, that the tax revenues increase).

Let us start with the case where the additional tax revenues are spent on the public consumption good. According to equations (21) and (19), two mechanisms determine how increased provision of the public consumption good influences welfare; (i) the relationship between welfare and the net interest rate, i.e. $V_{\rho}+\lambda R_{\rho}$ (which we discussed at some length above), and (ii) the impact of the public consumption good on the wage rate, $w_{G}=\omega_{G}\left(1+t_{w}\right)$. The sign of $w_{G}$ is ambiguous in general. On the one hand, increased provision of the public consumption good will change the union's rent from bargaining, as it affects both the utility of the bargaining outcome and the fall-back utility. On the other hand, it also affects the marginal valuation of wage increases, as the public consumption good may be either complementary with, or substitutable for, private consumption ${ }^{10}$. In a similar way, the sign of the second term on the right hand side of equation (22) is also ambiguous. Although it is common to have $K_{P}>0,{ }^{11}$ increasing the public input good has an ambiguous effect on the net wage rate. From the perspective of society, therefore, which public good that should be increased is determined by comparing (19) and (20). The incentives underlying public provision are further discussed in Subsection 4.1.2.

The result presented in Proposition 3 appears to stand in contrast to Fuest and Huber (1999), who consider labor and capital tax coordination in case the additional tax revenues are spent on a public consumption good. They argue that, in the presence of unemployment, a coordinated increase the labor or capital tax reduces welfare, if the labor demand is inelastic with respect to the gross wage rate. Although the wage rate will change as a consequence of policy coordination also in our framework, we do not find such a crucial influence of the labor demand elasticity. Our results show that the welfare effect is driven solely by the ability to reduce the

\footnotetext{
${ }^{10}$ See the appendix for a derivation.

${ }^{11}$ This is ensured by assuming that the public input good is a complement to private factors $\left(F_{L P}>0, F_{K P}>0\right)$ and both private factors are complements as well $\left(F_{K L}>0\right)$.
} 
net interest rate, which captures rents from (i) the capital owners and (ii) the union members (if $\omega_{\rho}>0$ ).

\subsubsection{Coordination of the capital tax rate}

So far, we have discussed the general cost benefit rule for coordination with respect to any of the two distortionary tax instruments. The coordination agreement most frequently analyzed in earlier literature is a marginal increase in the capital tax rate, which is carried out by all countries simultaneously. A coordinated increase in the capital tax rate, with the labor tax rate held constant, means that

$$
\left.\rho_{t_{c}}\right|_{\text {coord. }}=-\frac{K_{r} r_{t_{c}}+K_{w} w_{t_{c}}}{K_{r} r_{\rho}+K_{w} d w / d \rho}
$$

while the associated changes the gross interest rate and wage rate are given by equations (16)-(18). Therefore, the sign of $\rho_{t_{c}}$ is ambiguous in general.

In the special case where the utility function quasi-linear in private consumption $^{12}$, we have as a benchmark

$$
\begin{gathered}
\left.\rho_{t_{c}}\right|_{\text {coord. }}=-\frac{\rho}{1+t_{c}}<0, \\
\left.w_{t_{c}}\right|_{\text {coord. }}=\left.r_{t_{c}}\right|_{\text {coord. }}=\left.\omega_{t_{c}}\right|_{\text {coord. }}=0 .
\end{gathered}
$$

Consequently, as all countries increase their capital tax rate, the entire tax burden falls on the capital owners, since the capital endowment cannot evade worldwide taxation, whereas $d w / d \rho=w_{r} r_{\rho}$ and $w_{t_{c}}$ are proportional, since this special case implies that $\omega_{\rho}=0$. As the tax wedge on the labor market is not affected, the real allocation is not altered. Therefore, a joint increase in the capital tax rate unambiguously contributes to higher welfare; the total welfare change is positive in case the additional tax revenues are spent on the public consumption good (since $\omega_{G}=0$ ), and ambiguous if the additional tax revenues are spent on the public input good (since $\omega_{P}$ is ambiguous).

\subsubsection{Example: public expenditures and quasi-linear utility}

Let us briefly discuss each country's spending decision following a joint increase in the capital tax. To simplify, we consider the special case where the utility function is linear in private consumption. The corresponding factor price reactions are given by

\footnotetext{
${ }^{12}$ It has been common in earlier literature on optimal linear taxation under wage bargaining to assume a constant marginal utility of private consumption; see e.g. Boeters and Schneider (1999), Koskela and Schöb (2002) and Richter and Schneider (2001).
} 
equations (24)-(25). Following Schöb (1994), we denote by $M B F(G)$ and $M B F(P)$ the marginal benefit of public funds associated with the public consumption good and the public input good, respectively. These expressions can be derived by using the first order conditions for $G$ and $P$, i.e.

$$
\begin{gathered}
M B F(G)=\frac{d V / d G}{1-d R / d G}=\frac{V_{G}+V_{\omega} \omega_{G}}{1-R_{\omega} \omega_{G}}, \\
M B F(P)=\frac{d V / d P}{1-d R / d P}=\frac{V_{P}+V_{\omega} \omega_{P}}{1-R_{P}-R_{\omega} \omega_{P}} .
\end{gathered}
$$

Note that the special with a quasi-linear utility function implies $\omega_{G}=0$, so $M B F(G)=$ $V_{G}$. Since the policy choices already made at the national level mean $M B F(G)=$ $M B F(P)=\lambda$, the government will be indifferent between $G$ and $P$ in the uncoordinated equilibrium.

However, when all countries have agreed to marginally increase their capital tax and face the abovementioned reduction in the net interest rate, they may, nevertheless, strictly prefer to spend the additional tax revenue either on $G$ or $P$, depending on how the $M B F$ measures change due to capital tax coordination. The additional tax revenue is used to increase the provision of the public input good instead of the public consumption good if

$$
\left.\frac{\partial M B F(P)}{\partial t_{c}}\right|_{\text {coord. }}>\left.\frac{\partial M B F(G)}{\partial t_{c}}\right|_{\text {coord. }},
$$

which can be rewritten as ${ }^{13}$

$$
\left(K_{P}+K_{w} w_{P}\right)(1-d R / d P)>0 .
$$

Inequality (26) suggests that the individual spending decision of each country following a capital tax coordination deviates from the spending decision that is rational for all countries, collectively. Since $V_{\rho}+\lambda R_{\rho}<0$, combining equations (19) to (22) shows that it is welfare superior for all countries to increase the public input good instead of public consumption good provision if

$$
K_{P}+K_{w} w_{P}<0
$$

Consequently, for the special case where the public input good has no impact on the tax revenues, i.e. $d R / d P=0$, each country's incentive regarding the composition of additional public expenditures is exactly the opposite to the spending decision that gives the largest welfare gain for all countries.

\footnotetext{
${ }^{13}$ See the appendix for a derivation.
} 
Intuitively, it is not surprising that the individual countries may face incorrect incentives (from the perspective of society as a whole) with respect to additional public good provision. Since the tax coordination forces each government to deviate from its individually most preferred allocation, there is an incentive for the national government to use the pattern of public spending in order to again engage in fiscal competition by attracting mobile capital. ${ }^{14}$ By inspecting equation (27) and the counterpart to equation (26), i.e. the national decision rule to spend revenues on $G$, we can conclude the following as a more general result. If it is socially optimal to spend the additional tax revenues on the public input good, then each country will inevitably face the wrong incentive and spend it on the public consumption good, if the influence of the public input good on the tax revenue is non-negative. An analogous conclusion holds if the socially optimal decision is to spend the revenue on $G$.

\subsubsection{Coordination of the wage tax rate}

Instead of jointly increasing the capital tax rate, let us consider a coordinated change in the labor tax with the capital tax held constant. As has been pointed out by Bucovetsky and Wilson (1991), a joint increase in the labor tax will also affect the capital demand, which calls for an adjustment in the net interest rate. In contrast to the coordinated change in the capital tax, however, a joint increase in the labor tax adds to the tax wedge in the labor market. This, in turn, raises the gross wage and reduces employment. Therefore, the worldwide allocation is altered (even if we were to assume that the utility function is linear in private consumption).

Formally, from equations (8) and (14), we obtain the corresponding factor price changes, where the impact on the net interest rate is given by

$$
\left.\rho_{t_{w}}\right|_{\text {coord. }}=-\frac{K_{w} w_{t_{w}}}{d K / d \rho}
$$

If capital and labor are price complements, a coordinated increase in the labor tax reduces the worldwide capital demand, which calls for a reduction in the net interest rate to fully employ capital again. Therefore, given that $V_{\rho}+\lambda R_{\rho}<0$, this effect contributes to higher welfare.

\footnotetext{
${ }^{14}$ Theoretically, countries may also react by adjusting the wage tax in order to attract capital again. However, we exclude this possibility in this paper. For a model of partial tax coordination, see Wehke (2006).
} 


\subsection{A coordinated reform of government spending}

Following Keen and Marchand (1997), let us consider a revenue-neutral change in the composition of government spending by all countries. Keen and Marchand assume a competitive labor market, and a utility function in which the disutility of labor enters the private consumption term additively. Given these assumptions, the public consumption good does not affect the labor market equilibrium, and the result is clear-cut: the Nash equilibrium is characterized by a relative overprovision of the public input good. The intuition is that each country has an incentive to increase the domestic capital stock by increasing the provision of the public input good. The mechanisms emphasized are (i) a direct positive effect on the marginal product of capital and (ii) complementarity between labor and capital. Therefore, since there is no such link between the public consumption good and the marginal product of capital, each country will excessively use the public input good to attract capital at the expense of other countries.

If the tax rates are held constant, we have $d G=-d R>0$. The corresponding welfare change becomes

$$
\left.\frac{d W}{d G}\right|_{\text {coord. }} ^{d G=-d P}=\left.\frac{d W}{d G}\right|_{\text {coord. }} ^{d P=0}+\left.\frac{d W}{d P}\right|_{\text {coord. }} ^{d G=0} \frac{d P}{d G}=\left.W_{G}\right|_{\text {coord. }}-\left.W_{P}\right|_{\text {coord. }} .
$$

By analogy to the analysis carried out above, we can use the envelope theorem to determine

$$
\begin{aligned}
& \left.W_{P}\right|_{\text {coord. }}=\left.\left(V_{\rho}+\lambda R_{\rho}\right) \rho_{P}\right|_{\text {coord. }}, \\
& \left.W_{G}\right|_{\text {coord. }}=\left.\left(V_{\rho}+\lambda R_{\rho}\right) \rho_{G}\right|_{\text {coord. }} .
\end{aligned}
$$

Therefore, by using $V_{\rho}+\lambda R_{\rho}=-U_{C}(\hat{\lambda}-1)\left(K+\omega_{\rho} \omega L / w_{t_{w}}\right)$, we can derive the following result;

Proposition 4 In the noncooperative Nash equilibrium, the welfare effect of a joint revenue-neutral increase in the public consumption good and corresponding reduction in the public input good is given by

$$
\left.\frac{d W}{d G}\right|_{\text {coord. }} ^{d G=-d P}=U_{C}(\hat{\lambda}-1)\left(K+\omega_{\rho} \omega L / w_{t_{w}}\right)\left(\left.\rho_{P}\right|_{\text {coord. }}-\left.\rho_{G}\right|_{\text {coord. }}\right) .
$$

To interpret Proposition 4, let us assume that $V_{\rho}+\lambda R_{\rho}<0$. Then, by using equations (19) and (20), the welfare effect can be signed as follows; 


$$
\operatorname{sign}\left\{\left.\frac{d W}{d G}\right|_{\text {coord. }} ^{d G=-d P}\right\}=\operatorname{sign}\left\{K_{P}+K_{w}\left(w_{P}-w_{G}\right)\right\} .
$$

Therefore, the sign of the welfare effect depends on whether the public consumption good is complementary with, or substitutable for, private consumption as well as on the properties of the production function. The properties of the production function determine to what extent the wage rate responds to increased provision of the public input good as well as the magnitudes of the terms $K_{P}$ and $K_{w}$. An increase in the public consumption good may give rise to a positive, negative or no external effect on the rest of the world depending on

$$
\frac{d K}{d G}=K_{w} w_{G}\left\{\begin{array}{l}
> \\
= \\
<
\end{array}\right\} 0 \text { as } w_{G}\left\{\begin{array}{l}
< \\
= \\
>
\end{array}\right\} 0 .
$$

The possibility that $w_{G} \neq 0$ was assumed away by Keen and Marchand due to their choice of functional form of the utility function. For the public input good, on the other hand, there are two channels of influence on the capital stock

$$
\frac{d K}{d P}=K_{P}+K_{w} w_{P}
$$

The direct effect, $K_{P}$, is positive due to the complementarity between the public input good and the private production factors, whereas the indirect effect via the wage rate can go in either direction. Therefore, in contrast to a competitive labor market, this may offset the direct effect of higher public input provision.

\section{Concluding remarks}

In this paper, we consider factor income taxation and public good provision in small open economies, which compete for mobile capital and are characterized by involuntary unemployment due to wage bargaining between unions and firms. Each national government can spend its tax revenues on a public consumption good and a public input good. The paper contributes to the literature in two ways; (i) by characterizing the Nash equilibrium, which is based on the assumption that each country treats the world interest rate as well as the policies chosen by other countries as exogenous, and (ii) by considering policy coordination. We examine the welfare effects of a coordinated increase in each distortionary tax, where the additional tax revenues are spent either on the public consumption good or the public input good, and a revenue neutral reallocation of the public expenditures. 
We would like to emphasize two distinct results. First, tax coordination contributes to higher welfare, if it reduces the net interest rate (which counteracts the incentives associated with tax competition for mobile capital) and the net wage rate. Therefore, the welfare effects of coordination is interpretable in terms of the possibility to capture rents from the private sector. Second, the relative overprovision of the public input good derived by Keen and Marchand (1997) in the context of a competitive economy needs not necessarily carry over to an economy with wage bargaining. The reason is that increased provision of the public consumption good and the public input good may change the wage rate in either direction.

To further address the consequences of tax and expenditure policies in small open economies, as well as analyze the effects of policy coordination, there are several possible ways to extend the analysis carried out in the paper. One is to allow for a choice of work hours among the employed, which means an additional margin relevant for public policy. This is particularly interesting from the perspective of the labor income tax, as the employed individuals may not (themselves) choose the hours of work in an optimal way from society's point if view in an economy with involuntary unemployment (see Aronsson and Sjögren (2004a)). Another is to incorporate heterogeneity and redistribution into the analysis. This would also provide a natural framework for analyzing nonlinear tax instruments (instead of the linear instruments used in our paper). We hope to address these, and other, extensions in the future. 


\section{Appendix}

\section{Proof of Proposition 1}

Noting that $w_{t_{w}}=\omega+\left(1+t_{w}\right) \omega_{t_{w}}$, the first order condition with respect to the labor tax, i.e. $\mathcal{L}_{t_{w}}=0$, can be written as

$$
(\hat{\lambda}-1)\left[-L \omega_{t_{w}}+\left(1-t_{s}\right) L w_{t_{w}}\right]+(\omega-b) L_{w} w_{t_{w}}+\hat{\lambda}\left[t_{w} \omega L_{w} w_{t_{w}}+t_{c} \rho K_{w} w_{t \omega}\right]=0 .
$$

The corresponding condition for the capital tax is $\mathcal{L}_{t_{c}}=0$ and yields the following:

$$
\begin{aligned}
& (\hat{\lambda}-1)\left[-L \omega_{t_{c}}+\left(1-t_{s}\right)\left(L w_{t_{c}}+\rho K\right)\right]+(\omega-b)\left(L_{w} w_{t_{c}}+L_{r} \rho\right) \\
+ & \hat{\lambda}\left[t_{w} \omega\left(L_{w} w_{t_{c}}+L_{r} \rho\right)+t_{c} \rho\left(K_{w} w_{t_{c}}+K_{r} \rho\right)\right]=0 .
\end{aligned}
$$

Multiplying equation (29) by $\omega_{t_{c}}$ and equation (30) by $\omega_{t_{w}}$ enables us to combine both expressions to get

$$
\begin{aligned}
& (\hat{\lambda}-1)\left(1-t_{s}\right)\left(\omega L \omega_{t_{c}}-\rho K \omega_{t_{w}}\right)+(\omega-b)\left(L_{w} \omega \omega_{t_{c}}-L_{r} \rho \omega_{t_{w}}\right) \\
+ & \hat{\lambda}\left[t_{w} \omega\left(L_{w} \omega \omega_{t_{c}}-L_{r} \rho \omega_{t_{w}}\right)+t_{c} \rho\left(K_{w} \omega \omega_{t_{c}}-K_{r} \rho \omega_{t_{w}}\right)\right]=0 .
\end{aligned}
$$

After plugging in $L_{w}=F_{K K} / \Sigma, K_{r}=F_{L L} / \Sigma$ and $L_{r}=K_{w}=-F_{L K} / \Sigma$, where $\Sigma=$ $F_{L L} F_{K K}-\left(F_{L K}\right)^{2}$, and substituting equation (31) into (29) and (30), respectively, we arrive at the optimal tax formulas as given in the Proposition.

\section{Wage bargaining}

The first order condition for the net wage rate can be written as

$$
\Omega_{\omega}=0 \Rightarrow \widetilde{\Omega}_{\omega}=a \frac{\Upsilon_{\omega}}{\Upsilon}+(1-a) \frac{\pi_{\omega}}{\pi}=0,
$$

where

$$
\begin{gathered}
\pi_{\omega}=-L\left(1+t_{w}\right)<0 \\
\Upsilon_{\omega}=U_{C} \cdot\left[L+(\omega-b) L_{w}\left(1+t_{w}\right)\right]>0,
\end{gathered}
$$

The sign restriction on expression (34) follows from expressions (32) and (33). In deriving (34), we think of the net profit accruing to the union members as the average profit in the economy as a whole, which cannot be influenced by a small union's wage setting. 
The wage reaction to a change in $i, i=t_{c}, t_{w}, G, P$, is given by

$$
\omega_{i}=-\frac{\widetilde{\Omega}_{\omega i}}{\widetilde{\Omega}_{\omega \omega}},
$$

where $\widetilde{\Omega}_{\omega \omega}<0$ according to the second order condition. Furthermore,

$$
\widetilde{\Omega}_{\omega i}=a \frac{\partial}{\partial i}\left(\frac{\Upsilon_{\omega}}{\Upsilon}\right)+(1-a) \frac{\partial}{\partial i}\left(\frac{\pi_{\omega}}{\pi}\right)
$$

\section{The influence of the public consumption good on the wage rate}

Since $\operatorname{sign}\left(\omega_{i}\right)=\operatorname{sign}\left(\widetilde{\Omega}_{\omega i}\right)$, and $\pi_{\omega} / \pi$ is unaffected by a change in the public consumption, we are left with

$$
\begin{aligned}
\widetilde{\Omega}_{\omega G} & =a \frac{\partial}{\partial G}\left(\frac{\Upsilon_{\omega}}{\Upsilon}\right) \\
& =\frac{a \Upsilon_{\omega}}{U_{C} \Upsilon}\left[U_{C G}\left(U-U^{0}\right)-U_{C} \cdot\left(U_{G}-U_{G}^{0}\right)\right],
\end{aligned}
$$

where $U^{0}$ and $U_{G}^{0}$ are evaluated at $C^{0}$. The first term in brackets is positive (negative) if the public consumption good is complementary with (substitutable for) private consumption, i.e. $U_{C G}>(<) 0$, implying that an increase in $G$ increases (decreases) the marginal benefit of a wage increase. The second term is the increased (decreased) rent from bargaining facing the union if $U_{G}-U_{G}{ }^{0}>(<) 0$, which works to reduce (increase) the wage claims.

\section{The influence of the public input good on the wage rate}

Following the above procedure, we have

$$
\widetilde{\Omega}_{\omega P}=a \frac{\partial}{\partial P}\left(\frac{\Upsilon_{\omega}}{\Upsilon}\right)+(1-a) \frac{\partial}{\partial P}\left(\frac{\pi_{\omega}}{\pi}\right) .
$$

The first term on the right hand side of equation (35) can be written as

$$
\frac{\partial}{\partial P}\left(\frac{\Upsilon_{\omega}}{\Upsilon}\right)=\frac{1}{\Upsilon^{2}}\left[\Upsilon_{\omega P} \Upsilon-\Upsilon_{\omega} \Upsilon_{P}\right]
$$

where $\Upsilon_{\omega}$ is given by equation (34) and

$$
\begin{aligned}
\Upsilon_{P} & =U_{C} \cdot(\omega-b) L_{P}+\left(U_{C}-U_{C}^{0}\right)\left(1-t_{s}\right) \pi_{P}, \\
\Upsilon_{\omega P} & =U_{C}\left[L_{P}+(\omega-b) L_{w P}\left(1+t_{w}\right)\right] \\
& +U_{C C} \underbrace{\left[L+(\omega-b) L_{w}\left(1+t_{w}\right)\right]}_{=\Upsilon_{\omega} / U_{C}}\left[(\omega-b) L_{P}+\left(1-t_{s}\right) \pi_{P}\right] \\
& =U_{C}\left[L_{P}+(\omega-b) L_{w P}\left(1+t_{w}\right)\right]+\frac{U_{C C}}{U_{C}} \Upsilon_{\omega}\left[(\omega-b) L_{P}+\left(1-t_{s}\right) \pi_{P}\right] .
\end{aligned}
$$


Therefore,

$$
\begin{aligned}
\frac{\partial}{\partial P}\left(\frac{\Upsilon_{\omega}}{\Upsilon}\right) & =\frac{1}{\Upsilon^{2}}\left\{U_{C}\left[L_{P}+(\omega-b) L_{w P}\left(1+t_{w}\right)\right] \Upsilon+(\omega-b) L_{P} \frac{\Upsilon_{\omega}}{U_{C}}\left[U_{C C} \Upsilon-U_{C}^{2}\right]\right. \\
& \left.+\left(1-t_{s}\right) \pi_{P} \frac{\Upsilon_{\omega}}{U_{C}}\left[U_{C C} \Upsilon-U_{C}\left(U_{C}-U_{C}^{0}\right)\right]\right\}
\end{aligned}
$$

The first term in the upper line of equation (36) reflects the union's incentives to alter its wage claim, as an increase in the public input good changes the marginal benefit of a higher wage rate. On the one hand, the union will ceteris paribus demand higher wages as the public input good increases labor demand. On the other hand, the union wants the reduce (increase) the wage rate, if the additional public good provision increases (decreases) the wage responsiveness of labor demand. The second term in the upper line shows that the union has an incentive to ceteris paribus call for lower wages as the marginal utility of private consumption is decreasing, and the total rent from bargaining is increasing in the public input good. The term in the lower line of (36) will vanish if the utility is linear in consumption, and is ambiguous for $U_{C C}<0$ as this also implies $U_{C}-U_{C}^{0}<0$. Inspecting the second term on the right hand side of equation (35), we are able to write

$$
\frac{\partial}{\partial P}\left(\frac{\pi_{\omega}}{\pi}\right)=\frac{\partial}{\partial P}\left(\frac{-L\left(1+t_{w}\right)}{\pi}\right)=\frac{L\left(1+t_{w}\right)}{\pi}\left[\frac{\pi_{P}}{\pi}-\frac{L_{P}}{L}\right]
$$

Derivation of $w_{t_{w}}>0$

From $w=\omega\left(1+t_{w}\right)$, we have

$$
\begin{aligned}
w_{t_{w}} & =\left(1+t_{w}\right) \omega_{t_{w}}+\omega \\
& =\frac{-\widetilde{\Omega}_{\omega t_{w}}\left(1+t_{w}\right)+\widetilde{\Omega}_{\omega \omega} \omega}{\widetilde{\Omega}_{\omega \omega}},
\end{aligned}
$$

For $w_{t_{w}}>0$, the numerator of equation (37) must be is negative. Note first that

$$
-(1-a) \frac{\partial}{\partial t_{w}}\left(\frac{\pi_{\omega}}{\pi}\right)\left(1+t_{w}\right)+(1-a) \frac{\partial}{\partial \omega}\left(\frac{\pi_{\omega}}{\pi}\right) \omega=0,
$$

implying that we only need to analyze the sign of

$$
-\frac{\partial}{\partial t_{w}}\left(\frac{\Upsilon_{\omega}}{\Upsilon}\right)\left(1+t_{w}\right)+\frac{\partial}{\partial \omega}\left(\frac{\Upsilon_{\omega}}{\Upsilon}\right) \omega
$$

Therefore, 


$$
\begin{aligned}
\frac{\partial}{\partial t_{w}}\left(\frac{\Upsilon_{\omega}}{\Upsilon}\right)\left(1+t_{w}\right) & =\frac{1}{\Upsilon^{2}}\left\{w \Upsilon U_{C}\left[L_{w}+(\omega-b)\left(1+t_{w}\right) L_{w w}+\frac{(\omega-b)}{\omega} L_{w}\right]\right. \\
& +w \Upsilon U_{C C}\left[L+(\omega-b) L_{w}\left(1+t_{w}\right)\right]\left[(\omega-b) L_{w}-\left(1-t_{s}\right) L\right] \\
& \left.-w \Upsilon_{\omega} U_{C}\left[(\omega-b) L_{w}-\left(1-t_{s}\right) L\right]\right\}
\end{aligned}
$$

and

$$
\begin{aligned}
\frac{\partial}{\partial \omega}\left(\frac{\Upsilon_{\omega}}{\Upsilon}\right) \omega & =\frac{1}{\Upsilon^{2}}\left\{w \Upsilon U_{C}\left[L_{w}+(\omega-b)\left(1+t_{w}\right) L_{w w}+L_{w}\right]\right. \\
& +w \Upsilon U_{C C}\left[L+(\omega-b) L_{w}\left(1+t_{w}\right)\right]\left[(\omega-b) L_{w}+\frac{L}{\left(1+t_{w}\right)}\right] \\
& \left.-w \Upsilon_{\omega} U_{C}\left[(\omega-b) L_{w}-\left(1-t_{s}\right) L\right]\right\}
\end{aligned}
$$

Consequently, we can write the numerator of equation (37) as follows:

$-\widetilde{\Omega}_{\omega t_{w}}\left(1+t_{w}\right)+\widetilde{\Omega}_{\omega \omega} \omega=\frac{1}{\Upsilon}\left\{w U_{C} L_{w}\left[1-\frac{(\omega-b)}{\omega}\right]+w L \frac{U_{C C} \Upsilon_{\omega}}{U_{C}}\left[\frac{1}{\left(1+t_{w}\right)}+\left(1-t_{s}\right)\right]\right\}$.

Thus, as $\Upsilon, U_{C}, \Upsilon_{\omega},[1-(\omega-b) / \omega],\left(1+t_{w}\right),\left(1-t_{s}\right)>0$ and $U_{C C}, L_{w}<0$ we can also conclude that $w_{t_{w}}>0$.

Derivation of $V_{\rho}+\lambda R_{\rho}=-U_{C}(\hat{\lambda}-1)\left(K+\omega_{\rho} \omega L / w_{t_{w}}\right)$

Note that

$$
\begin{aligned}
& V_{\rho}+\lambda R_{\rho} \\
& =U_{C} K+\lambda t_{c} K \\
& +r_{\rho}\left\{U_{C} \cdot\left[(\omega-b)\left(L_{r}+L_{w} w_{r}\right)+L \omega_{r}+\left(1-t_{s}\right)\left(-K-L w_{r}\right)\right]\right. \\
& \left.+\lambda\left[t_{s}\left(-K-L w_{r}\right)+t_{w} L \omega_{r}+t_{w} \omega\left(L_{r}+L_{w} w_{r}\right)+t_{c} \rho\left(K_{r}+K_{w} w_{r}\right)\right]\right\} \\
& +\omega_{\rho}\left\{U_{C} \cdot\left[(\omega-b) L_{w}\left(1+t_{w}\right)+L-\left(1-t_{s}\right) L\left(1+t_{w}\right)\right]\right. \\
& \left.+\lambda\left[-t_{s} L\left(1+t_{w}\right)+t_{w} L+t_{w} \omega L_{w}\left(1+t_{w}\right)+t_{c} \rho K_{w}\left(1+t_{w}\right)\right]\right\},
\end{aligned}
$$

where $r_{\rho}=\left(1+t_{c}\right)$. By inserting the optimal tax rates the last term in curly brackets can be rearranged to

$$
-\frac{U_{C} \omega L(\hat{\lambda}-1)}{w_{t_{w}}} .
$$

Note that the first order condition for the capital tax, $V_{t_{c}}+\lambda R_{t_{c}}=0$, can be written

$$
\begin{aligned}
0 & =\lambda \rho K+r_{t_{c}}\left\{U_{C} \cdot\left[(\omega-b)\left(L_{r}+L_{w} w_{r}\right)+L \omega_{r}+\left(1-t_{s}\right)\left(-K-L w_{r}\right)\right]\right. \\
& \left.+\lambda\left[t_{s}\left(-K-L w_{r}\right)+t_{w} L \omega_{r}+t_{w} \omega\left(L_{r}+L_{w} w_{r}\right)+t_{c} \rho\left(K_{r}+K_{w} w_{r}\right)\right]\right\}
\end{aligned}
$$


where $r_{t_{c}}=\rho$, and the term in curly brackets exactly coincides with the first term in curly bracket in equation (38). Thus, by inserting $\{\cdot\}=-\lambda K$ into the (38), we have

$$
\begin{aligned}
V_{\rho}+\lambda R_{\rho} & =U_{C} K+\lambda t_{c} K-\lambda K\left(1+t_{c}\right) \\
& +\omega_{\rho}\left\{U_{C} \cdot\left[(\omega-b) L_{w}\left(1+t_{w}\right)+L-\left(1-t_{s}\right) L\left(1+t_{w}\right)\right]\right. \\
& \left.+\lambda\left[-t_{s} L\left(1+t_{w}\right)+t_{w} L+t_{w} \omega L_{w}\left(1+t_{w}\right)+t_{c} \rho K_{w}\left(1+t_{w}\right)\right]\right\} .
\end{aligned}
$$

In order to simplify this expression, we make use of the first-order condition for the labor tax, $V_{t_{w}}+\lambda R_{t_{w}}=0$, i.e.

$$
\begin{aligned}
0 & =U_{C}\left[\omega_{t_{w}} L+(\omega-b) L_{w} w_{t_{w}}-\left(1-t_{s}\right) L w_{t_{w}}\right] \\
& +\lambda\left[-t_{s} L w_{t_{w}}+\omega L+t_{w} L \omega_{t_{w}}+t_{w} \omega L_{w} w_{t_{w}}+t_{c} \rho K_{w} w_{t_{w}}\right]
\end{aligned}
$$

which can be rearranged to

$$
\begin{aligned}
& \omega_{t_{w}}\left\{U_{C}\left[L+(\omega-b) L_{w}\left(1+t_{w}\right)-\left(1-t_{s}\right) L\left(1+t_{w}\right)\right]\right. \\
& \left.+\lambda\left[-t_{s} L\left(1+t_{w}\right)+t_{w} L+t_{w} \omega L_{w}\left(1+t_{w}\right)+t_{c} \rho K_{w}\left(1+t_{w}\right)\right]\right\} \\
& =U_{C}\left[-(\omega-b) L_{w} \omega+\left(1-t_{s}\right) L \omega\right]+\lambda\left[t_{s} L \omega-\omega L-t_{w} \omega L_{w} \omega-t_{c} \rho K_{w} \omega\right],
\end{aligned}
$$

Inserting this formula into equation (39), we have

$$
V_{\rho}+\lambda R_{\rho}=-U_{C} K(\hat{\lambda}-1)-\frac{\omega_{\rho} \omega U_{C}}{\omega_{t_{w}}}\left[(\omega-b) L_{w}+(\hat{\lambda}-1)\left(1-t_{s}\right) L+\hat{\lambda}\left(t_{w} \omega L_{w}+t_{c} \rho K_{w}\right)\right]
$$

Finally, using the optimal tax rates in the Nash equilibrium in equation (40), we find that

$$
-(\omega-b) L_{w}-(\hat{\lambda}-1)\left(1-t_{s}\right) L-\hat{\lambda}\left(t_{w} \omega L_{w}+t_{c} \rho K_{w}\right)=-(\hat{\lambda}-1) L \omega_{t_{w}} / w_{t_{w}}
$$

So

$$
\begin{aligned}
V_{\rho}+\lambda R_{\rho} & =-U_{C} K(\hat{\lambda}-1)-\frac{\omega_{\rho}}{w_{t_{w}}} \omega U_{C}(\hat{\lambda}-1) L \\
& =-(\hat{\lambda}-1) U_{C}\left[K+\frac{\omega_{\rho}}{w_{t_{w}}} \omega L\right] .
\end{aligned}
$$


as given in the text, where the only term whose sign is ambiguous is $\omega_{\rho}$ [see equation (41) below].

\section{Factor price changes in response to capital tax coordination}

By totally differentiating $\bar{K}=K(w, r, P)$ and taking $\omega=\omega\left(t_{w}, r, \rho, P, G\right)$ from the Nash bargaining result into account, we have

$$
\begin{aligned}
\left.\rho_{t_{c}}\right|_{\text {coord. }} & =-\frac{d K / d t_{c}}{d K / d \rho} \\
& -\frac{K_{r} r_{t_{c}}+K_{w}\left(1+t_{w}\right) \omega_{r} r_{t_{c}}}{K_{r} r_{\rho}+K_{w}\left(1+t_{w}\right) \omega_{r} r_{\rho}+K_{w}\left(1+t_{w}\right) \omega_{\rho}} \\
& =-\frac{\rho}{\left(1+t_{c}\right)} \frac{K_{r}+K_{w}\left(1+t_{w}\right) \omega_{r}}{K_{r}+K_{w}\left(1+t_{w}\right) \omega_{r}+K_{w}\left(1+t_{w}\right) \omega_{\rho} /\left(1+t_{c}\right)} \\
& =-\frac{\rho}{\left(1+t_{c}\right)}\left[1-\frac{K_{w}\left(1+t_{w}\right) \omega_{\rho} /\left(1+t_{c}\right)}{K_{r}+K_{w}\left(1+t_{w}\right) \omega_{r}+K_{w}\left(1+t_{w}\right) \omega_{\rho} /\left(1+t_{c}\right)}\right] .
\end{aligned}
$$

For the wage response to a change in the net interest rate (at a constant $r$ ), we need $\omega_{\rho}=-\widetilde{\Omega}_{\omega \rho} / \widetilde{\Omega}_{\omega \omega}$. In detail, we have the following for $\widetilde{\Omega}_{\omega \rho}$ :

$$
\frac{\partial}{\partial \rho}\left(\frac{\pi_{\omega}}{\pi}\right)=0
$$

and

$$
\frac{\partial}{\partial \rho}\left(\frac{\Upsilon_{\omega}}{\Upsilon}\right)=\frac{K \Upsilon_{\omega}}{\Upsilon}\left(\frac{U_{C C}}{U_{C}}-\frac{U_{C}-U_{C}^{0}}{\Upsilon}\right)
$$

The wage response can, therefore, be written as

$$
\omega_{\rho}=-\frac{a}{\widetilde{\Omega}_{\omega \omega}} \frac{K \Upsilon_{\omega}}{\Upsilon}\left(\frac{U_{C C}}{U_{C}}-\frac{U_{C}-U_{C}^{0}}{\Upsilon}\right) .
$$

Thus, for a joint increase in the capital tax, the net interest rate changes according to

$$
\left.\rho_{t_{c}}\right|_{\text {coord. }}=-\frac{\rho}{\left(1+t_{c}\right)}\left[1+\frac{a\left(\Upsilon_{\omega} / \Upsilon\right) \cdot\left(K / \widetilde{\Omega}_{\omega \omega}\right)\left[U_{C C} / U_{C}-\left(U_{C}-U_{C}^{0}\right) / \Upsilon\right]}{K_{r}+K_{w}\left(1+t_{w}\right) \omega_{r}+K_{w}\left(1+t_{w}\right) \omega_{\rho} /\left(1+t_{c}\right)}\right]
$$

\section{Derivation of equation (26)}

The marginal tax revenues from higher public spending are given by

$$
R_{\omega} \omega_{G}=0,
$$


since we restrict our example to a quasi-linear utility function, and

$$
\begin{aligned}
R_{P}+R_{\omega} \omega_{P} & =\left(1-t_{s}\right) \pi_{P}+t_{c} \rho K_{P}+t_{w} \omega L_{P}+\left(1-t_{s}\right) \pi_{w}\left(1+t_{w}\right) \omega_{P} \\
& +t_{c} \rho K_{w}\left(1+t_{w}\right) \omega_{P}+t_{w} L \omega_{P}+t_{w} \omega L_{w}\left(1+t_{w}\right) \omega_{P}
\end{aligned}
$$

respectively. For the special case where the utility function is linear in private consumption, a joint increase in the capital tax does not affect the real allocation. Consequently, in equation (43) only the terms that contain $t_{c} \rho$ will change due to a capital tax coordination. Since $V_{G}=U_{G}$ and $V_{P}+V_{\omega} \omega_{P}=U_{C}\left[L \omega_{P}+(\omega-b) L_{P}+\right.$ $\left.\left(1-t_{s}\right) \pi_{P}\right]+U_{C}\left[L+(\omega-b) L_{w}\left(1+t_{w}\right)\right] \omega_{P}$ are not altered by a joint increase in the capital tax and the subsequent change in $\rho$, we have the following:

$$
\left.\frac{\partial M B F(G)}{\partial t_{c}}\right|_{\text {coord. }}=0
$$

and

$$
\begin{aligned}
\left.\frac{\partial M B F(P)}{\partial t_{c}}\right|_{\text {coord. }} & =\frac{\left(V_{P}+V_{\omega} \omega_{P}\right) \cdot\left(\left.\frac{\partial R_{P}}{\partial t_{c}}\right|_{\text {coord. }}+\left.\frac{\partial R_{\omega}}{\partial t_{c}}\right|_{\text {coord. }} \omega_{P}\right)}{\left(1-R_{P}-R_{\omega} \omega_{P}\right)^{2}} \\
& =\left.\frac{M B F(P) \cdot\left[K_{P}+K_{w}\left(1+t_{w}\right) \omega_{P}\right]}{\left(1-R_{P}-R_{\omega} \omega_{P}\right)} \frac{\partial\left(t_{c} \rho\right)}{\partial t_{c}}\right|_{\text {coord. }} .
\end{aligned}
$$

Using $M B F(P)>0$, the expression $\partial\left(t_{c} \rho\right) /\left.\partial t_{c}\right|_{\text {coord. }}=\rho /\left(1+t_{c}\right)>0$ as well as the assumption that the model is stable in the sense that $1-d R / d P>0$, yields the inequality (26) as given in the text. 


\section{References}

[1] Aronsson, T., M. Markström and T. Sjögren (2005): "Public Provision of Private Goods and Equilibrium Unemployment", FinanzArchiv 61, 353-367.

[2] Aronsson, T. and T. Sjögren (2004a): "Is the Optimal Labor Income Tax Progressive in a Unionized Economy?", Scandinavian Journal of Economics 106, 661-675.

[3] Aronsson, T. and T. Sjögren (2004b): "Efficient Taxation, Wage Bargaining and Policy Coordination", Journal of Public Economics 88, 2711-2725.

[4] Boeters, S. and K. Schneider (1999): "Government versus Union: The Structure of Optimal Taxation in a Unionized Labor Market", FinanzArchiv 56, 174-187.

[5] Bucovetsky, S. and J. D. Wilson (1991): "Tax Competition with Two Tax Instruments", Regional Science and Urban Economics 21, 333-350.

[6] Fuest, C. and B. Huber (1997): "Wage Bargaining, Labor-Tax Progression, and Welfare", Journal of Economics 66, 127-150.

[7] Fuest, C. and B. Huber (1999): "Tax Coordination and Unemployment", International Tax and Public Finance 6, 7-26.

[8] Keen, M. and M. Marchand (1997): "Fiscal Competition and the Pattern of Public Spending", Journal of Public Economics 66, 33-53.

[9] Koskela, E. and R. Schöb (2002): "Optimal Factor Income Taxation in the Presence of Unemployment", Journal of Public Economic Theory 4, 387-404.

[10] Lejour, A. M. and H. A. Verbon (1996): "Capital Mobility, Wage Bargaining and Social Insurance Policies in an Economic Union", International Tax and Public Finance 3, 495-513.

[11] Marceau, N. and R. Boadway (1994): "Minimum Wage Legislation and Unemployment Insurance as Instruments for Redistribution", Scandinavian Journal of Economics 96, 67-81.

[12] Matsumoto, M. (1998): "A Note on Tax Competition and Public Input Provision", Regional Science and Urban Economics 28, 465-473.

[13] McMillan, J. (1979), "A Note on the Economics of Public Intermediate Goods", Public Finance 34, 293-299. 
[14] Mintz, J. and H. Tulkens (1986): "Commodity Tax Competition between Member States of a Federation: Equilibrium and Efficiency", Journal of Public Economics 29, 133-172.

[15] Richter W. F. and K. Schneider (2001): "Taxing Mobile Capital with Labor Market Imperfections", International Tax and Public Finance 8, 245-262.

[16] Schöb, R. (1994): "On Marginal Cost and Benefit of Public Funds", Public Finance 49, 87-106.

[17] Wehke, S. (2006): "Tax Competition and Partial Coordination", FinanzArchiv $62,416-436$.

[18] Wilson, J. D. (1986): "A Theory of Interregional Tax Competition", Journal of Urban Economics 19, 296-315.

[19] Wilson, J. D. (1999): "Theories on Tax Competition", National Tax Journal $52,269-304$.

[20] Zodrow, G. R. and P. Mieszkowski (1986): "Pigou, Tiebout, Property Taxation, and the Underprovision of Local Public Goods", Journal of Urban Economics 19, 356-370. 